\title{
Screening for the Severity of Illicit Drug Use among the "Tokhang" Responders in the Philippines: Basis for Community-Based Drug Rehabilitation Program
}

\author{
Narcie Faith Pilon Amista ${ }^{1}$ and Baronese Peters ${ }^{1,2}$ \\ ${ }^{1}$ Department of Adiction Science, School of Graduate Studies \\ Sahmyook University - Gongneung Nowon-gu P.O. Box 118,130-650, Seoul, Korea \\ Email: faixee0529 [AT] gmail.com \\ ${ }^{2}$ Department of Counseling Psychology \\ Sahmyook University Gongneung Nowon-gu P.O. Box 118,130-650, Seoul, Korea \\ Email: profbaronese [AT] gmail.com
}

\begin{abstract}
Substance use has turned into a worldwide phenomenon influencing practically every country. Alcohol and other drugs are rapidly becoming a problem for public health. The primary purpose of this study is to screen the severity levels of drug use among "Tokhang" (Cebuano word that implies Tok-tok Hangyo, where police staff knocks the doors of an affirmed user or pusher, asking him/her politely to surrender to the police so that he/she will be checked for further assessment) responders in the municipality of Don Carlos, Philippines. The study results will provide baseline data on the severity of drug use among the responders. It is vital to know the severity level so that appropriate interventions will be formulated. This study utilized a descriptive-correlational survey design to determine the relationship between the sociodemographic profile and World Health Organization-Alcohol, Smoking and Substance Involvement Screening Test (WHO-ASSIST) among the "Tokhang" responders. The majority of the Tokhang respondents were male comprising $999(99.3 \%)$ of the study population. In terms of marital status, 467 respondents were married (45.5\%), 377 were single (37.5\%), and 170 belonged in cohabitation (16.9\%). In terms of educational attainment, 338 respondents reached high school level (33.7\%.) and were 258 high school graduates (25.7\%). Tobacco products has a $(M=19.17)$ followed with alcoholic beverages with $(M=17.89)$, and lastly, amphetamine-type stimulants such as shabu were rated as $(M=3.64)$ and described as moderate risk level, respectively. The initial results of the study will provide the basis for the community-based rehabilitation program for low and moderate risk drug use and moderate to high alcohol and tobacco use among the Tokhang responders. The Brief Intervention for Referral Treatment will be followed to implement and evaluate the program focusing on these substances.
\end{abstract}

Keywords - Community-based rehabilitation program, SBIRT, severity of drug use, WHO- ASSIST tool

\section{INTRODUCTION}

Substance use has turned into a worldwide phenomenon influencing practically every country. However, there are variations in the attributes and degree of substance use in every country. The most used or abused substances worldwide are cigarettes, cannabis, and alcohol. Alcohol and other related issues are increasingly becoming a public health concern. Abuse of alcohol represents one of the primary causes of preventable death, ailment, and injury. Other common substances are inhalants, heroin, and cocaine. The abuse of these substances is related to expanding the amount consumed, recurrence of utilization, and groups involved [1].

In 2002, illicit substance production in the Southern part of Asia was reaching gargantuan proportions, especially with the manufacture of opiates and its first derivative, heroin [2]. Afghanistan, Myanmar, and Laos are known to be the three most prominent outlets of illegal opium worldwide. The illegal manufacturing of Amphetamine-Type Stimulants (ATS), especially methamphetamine in Southeast Asia, is occurring in China and Myanmar and is additionally of noteworthy concern [2]. Several reports show that ephedrine, used for illicitly delivering methamphetamine in Southeast Asia, is transmitted and carried out of China and India, while caffeine, the component utilized for creating methamphetamine tablets, is chiefly pirated in Myanmar through its Thailand border. The literature explains that there is widespread abuse of a substance [2].

Nowadays, the issue of substance use remains a significant social issue in the Philippines. In 2004, the number of 
drug users across the country was found to be approximately 3.4 million [3]. This drug issue persists regardless of the substantial punishments, including death sentence, law enforcements on the sale and utilization of prohibited drugs. One aggravating aspect of this issue is that drug users are getting younger. The figures measured this past decade imply a trend of decreasing age of drug users. In the 1950s, the age of drug users extended between 40-55 years. In the 1980s, the average age of drug users was 25. More recent data shows that the age of initiating drug use was 8 to 9 years [4].

Drug users profile shows that a more significant proportion of drug dependents in the country are poly-drug users, that is, using several different illicit drugs. In general, pleasure is the primary reason for drug abuse. There are similar situations in which illegal drugs are used by people to adjust to the demands of their work, similar to those working in graveyard shifts, or working for extended time periods. The high accessibility of illegal drugs urges them to take illegal drugs. Methamphetamine hydrochloride, or shabu, remains the most abused drug in the Philippines, followed by marijuana or cannabis Sativa, and MDMA or ecstasy. Ecstasy, known as the "party drug," is generally used for gatherings and nightlife and considered as an overpriced drug in the market. Likewise, solvents and different inhalants are an inclination and generally abused by street children [5].

The "Oplan Tokhang" initiative of the Philippine National Police (PNP) is a national law requirement project that was enforced throughout the Philippines. This was propelled as a component of the crusade to caution illegal drug traffickers and users to stop their activities. "Oplan Tokhang" is a Visayan word that implies Tok-tok Hangyo, where police staff knocks the doors of an affirmed user or pusher, asking him/her to surrender to the police all together so that he/she will be checked for further assessment. The people who surrendered voluntarily were named "Tokhang responders."

The Philippine Information Agency (2017) elaborated that after the announcement of President Duterte's war on drugs, about 88,940 drug pushers willfully surrendered, while 1,266,966 persons who use drugs (PWUD) deliberately submitted to authorities. UNODC reported $95-99 \%$ of the drug surrenderees would need community-based drug rehabilitation intervention, 3\%-4\% would need outpatient/non-residential drug rehabilitation, and 1\% would need residential drug rehabilitation $[6,7,8]$. Through the efforts of the Local Government Unit of Don Carlos, Bukidnon, the PNP was able to endorse 1,192 PWUDs to the Municipal Health Officer.

To assess the effectiveness of the community-based drug recovery program (CDRP) for drug users in the municipality of Don Carlos, we adapted the public health model of Screening, Brief Intervention, Referral, and Treatment (SBIRT). SBIRT consists of three major components: Screening - a healthcare provider evaluates the client's substance use risk score by using a standardized screening tool; Brief Intervention (BI) - a healthcare professional engages a patient showing risky substance use behaviors in a short conversation, providing feedback and advice; Referral to Treatment (RT) - a healthcare provider provides a referral to treatment centers for patents who are screened as needing additional services [9].

This study aims to screen the Tokhang responders to determine the severity level of their drug use. Tokhang responders, who had low to moderate risk for drug use and moderate to high risk for alcohol and tobacco, were required to take part in the CDRP. PAGE SIZE

All material on each page should fit within a rectangle of $18 \times 23.5 \mathrm{~cm}$ (7" x 9.25"), centered on the page, beginning $2.54 \mathrm{~cm}(1 ")$ from the top of the page and ending with $2.54 \mathrm{~cm}(1 ")$ from the bottom. The right and left margins should be $1.9 \mathrm{~cm}\left(.75^{\prime \prime}\right)$.

\section{METHOD}

This study utilized a descriptive-correlational survey design to determine the relationship between the independent and dependent variables used in the study. The survey described the characteristics of the responders and the severity level of their drug use. Data were encoded into the Statistical Program for the Social Sciences (SPSS) version 23 for analysis.

The study participants were the Tokhang responders identified in Don Carlos, Bukidnon. The inclusion criteria for the participants were (1) male or female, (2) 15 years old and above, (3) currently listed in the PNP master list, (4) a resident of Don Carlos, Bukidnon, and (5) voluntarily consented to participating in this study. Drug users who did not surrender to the authorities, and names who were not found in the master list were excluded from this study.

The independent variables were the socio-demographic characteristics such as gender, age, religion, educational attainment, and Socio-Economic Status (SES). The dependent variable was the WHO-ASSIST. WHO-ASSIST was intended to screen for the issue or dangerous use of tobacco, alcohol, cannabis, cocaine, amphetamine-type stimulants (ATS), sedatives, hallucinogens, inhalants, opioids, and other drugs. A risk score is received for every substance which is either a "low," "moderate," or "high" risk classification. This classification decides the type of intervention required ("none," "brief intervention," or "brief intervention plus referral") [7]. The ASSIST constructs are measured using selfreported responses to questionnaire items. It provides data on (a) the substances people have ever utilized as a part of in their lifetime, (b) the substances they have used in the previous three months, (c) issues identified with substance use, (d) danger of current or future harm, (e) reliance, and (f) injecting drug use. The ASSIST can caution people at risk of 
developing problems in the future related to their substance use and also provides a chance to begin discussions with a client about their substance use. It also recognizes substance use as a contributing factor to the presenting illness. The ASSIST can be connected to a brief intervention to help high-risk substance users to reduce or stop their drug use, and thus evade destructive outcomes of substance use [10].

\section{RESULT}

The descriptive statistics of the respondents' socio-demographic characteristics and other measures are presented in Table 1. A total of 1,006 respondents participated in this study. The analytic sample consisted of $999(99.30 \%)$ males and $7(.7 \%)$ females. Age was categorized into groups, with the 21-30 years old group constituting the largest at 455 $(45.40 \%)$ respondents. The 51 years and above group was the smallest with $22(1.90 \%)$ respondents. Of the respondents, 935 (93.3\%) participants were Roman Catholic, 35 (3.5\%) were Baptist, 22 (2.2\%) were Born-Again, and 12 (1.2\%) were Seventh-day Adventist (SDA). In terms of marital status, most respondents, 457 (45.5\%), were married, 377 $(37.50 \%)$ were single, and $170(6.9 \%)$ were cohabiting. In their educational attainment, most of the respondents, 338 $(33.7 \%)$ reached high school level, followed with $258(25.7 \%)$ high school graduates. SES was categorized into the largest "Low" group with $673(66.9 \%)$ respondents, "Low Average" with 163 (16.2\%), "High Average" with 122 (12.1\%), and "High" with 48 (4.8\%). Thus, these findings implied that the Tokhang responders were young adults, male, married, reached high school level, mostly in low SES, and have religious affiliations.

Table 1: General characteristics of respondents and other measures related to "Tokhang Responders"

\begin{tabular}{|c|c|c|}
\hline Variable & Number of Respondents (n) & Percentage (\%) \\
\hline \multicolumn{3}{|l|}{ Gender } \\
\hline Male & 999 & 99.30 \\
\hline Female & 7 & .70 \\
\hline \multicolumn{3}{|l|}{ Age } \\
\hline 20 and below & 233 & 23.20 \\
\hline $21-30$ & 455 & 45.40 \\
\hline $31-40$ & 230 & 22.90 \\
\hline $41-50$ & 66 & 6.60 \\
\hline $51-60$ & 22 & 1.90 \\
\hline \multicolumn{3}{|l|}{ Religion } \\
\hline Roman Catholic & 935 & 93.1 \\
\hline Baptist & 35 & 3.5 \\
\hline Born Again & 22 & 2.2 \\
\hline SDA & 12 & 1.2 \\
\hline \multicolumn{3}{|l|}{ Marital Status } \\
\hline Single & 377 & 37.50 \\
\hline Married & 457 & 45.50 \\
\hline Cohabitation & 170 & 17.00 \\
\hline \multicolumn{3}{|l|}{ Educational Attainment } \\
\hline Elementary level & 150 & 14.90 \\
\hline Elementary grad. & 112 & 11.20 \\
\hline High school level & 338 & 33.70 \\
\hline High school grad. & 258 & 25.70 \\
\hline College level & 120 & 12.00 \\
\hline College graduate & 26 & 2.60 \\
\hline \multicolumn{3}{|l|}{ Socio-Economic Status } \\
\hline Low & 673 & 66.9 \\
\hline Low Average & 163 & 16.2 \\
\hline High Average & 122 & 12.1 \\
\hline High & 48 & 4.8 \\
\hline
\end{tabular}


The initial screening among the Tokhang responders is shown in Table 2. It can be derived that Tobacco products, $(M=19.17)$ followed by Alcoholic beverages $(M=17.89)$, and lastly, the ATS such as shabu were rated as $(M=3.64)$, and described as moderate risk level, respectively. This finding formed the basis for the community-based rehabilitation program for the low and moderate risk for drug use and moderate to high for alcohol and tobacco among Tokhang responders.

Table 2: The range of WHO-ASSIST score among Tokhang responders

\begin{tabular}{lcc}
\hline Variables & Mean & Risk level \\
\hline Tobacco products & 19.17 & Moderate \\
Alcohol beverages & 17.90 & Moderate \\
Cannabis & 1.53 & Low \\
Cocaine & .08 & Low \\
Amphetamine-type Stimulants & 3.64 & Moderate \\
Inhalants & .03 & Low \\
Sedative or sleeping pills & .00 & Low \\
Hallucinogens & .00 & Low \\
Opioids & .05 & Low
\end{tabular}

*Scoring: Low $=0-3$, Moderate $=4-26$, High $=27$ and above

Table 3 shows a significant age-related effect in the use of opioids $(F=4.27, p<.05)$. A finding is shown by Scheffe post hoc test that ages 41-50 have a substantial outcome relative to the other age groups.

Table 3: Results of the severity level of substance use among tokhang respondents and age

\begin{tabular}{|c|c|c|c|c|c|c|c|}
\hline \multicolumn{8}{|c|}{ One-way ANOVA } \\
\hline \multirow[b]{2}{*}{ Variables } & $\begin{array}{l}20 \text { and } \\
\text { below }^{\mathrm{a}}\end{array}$ & $21-30^{b}$ & $31-40^{c}$ & $41-50^{d}$ & $\begin{array}{l}51 \text { and } \\
\text { above }^{\mathrm{e}}\end{array}$ & & \\
\hline & $M(S D)$ & $M(S D)$ & $M(S D)$ & $M(S D)$ & $M(S D)$ & $\boldsymbol{F}$ & Scheffe \\
\hline Tobacco & $18.36(10.35)$ & $18.29(10.81)$ & $19.03(10.88)$ & $17.79(11.37)$ & $17.47(13.98)$ & 0.29 & \\
\hline Alcohol & $17.10(8.30)$ & $17.91(8.36)$ & $17.51(8.61)$ & $19.00(8.46)$ & $16.05(10.86)$ & 0.96 & \\
\hline Cannabis & $1.49(3.80)$ & $0.98(2.64)$ & $1.23(2.89)$ & $1.14(2.16)$ & $1.47(2.61)$ & 1.25 & \\
\hline Cocaine & $0.00(.00)$ & $0.07(0.79)$ & $0.01(0.20)$ & $0.00(0.00)$ & $0.00(0.00)$ & 1.04 & \\
\hline Meth & $3.05(5.48)$ & $2.51(5.16)$ & $2.77(4.90)$ & $3.21(4.94)$ & $2.63(4.89)$ & 0.58 & \\
\hline Inhalants & $0.05(0.62)$ & $0.03(0.34)$ & $0.00(0.00)$ & $0.00(0.00)$ & $0.00(0.00)$ & 0.63 & \\
\hline Hallucinogens & $0.00(0.00)$ & $0.01(0.14)$ & $0.00(0.00)$ & $0.00(0.00)$ & $0.00(0.00)$ & 0.03 & \\
\hline Opioids & $0.00(0.00)$ & $0.02(0.42)$ & $0.00(0.00)$ & $0.47(3.25)$ & $0.00(0.00)$ & 4.27 & $d / b^{*}$ \\
\hline
\end{tabular}

$* p<.05, * * p<.001$ 
Table 4 shows the major difference between religion and the degree of seriousness of drug use among Tokhang responders. It can be seen that the Tokhang responders have a significant effect on the use of Methamphetamine $(\mathrm{F}=4.53, \mathrm{p}<.05)$. In other words, the Born-Again group has shown a significant difference in the use of Methamphetamine compared to other religious groups. Similar results were found for the use of inhalants, where the Born-Again group has shown a significant difference compared to the other religious groups. $(\mathrm{F}=7.97, \mathrm{p}<.01)$.

Table 4: Results of severity level for substance use among tokhang responders and religion

\begin{tabular}{|c|c|c|c|c|c|c|}
\hline \multirow[b]{3}{*}{ Variables } & \multicolumn{5}{|c|}{ One-way ANOVA } & \multirow[b]{3}{*}{ Scheffe } \\
\hline & $\begin{array}{l}\text { Roman } \\
\text { Catholic }^{\mathrm{a}}\end{array}$ & Baptist $^{\mathrm{b}}$ & $\mathrm{SDA}^{\mathrm{c}}$ & Born Again $^{\mathrm{d}}$ & \multirow[b]{2}{*}{$F$} & \\
\hline & $M(S D)$ & $M(S D)$ & $M(S D)$ & $M(S D)$ & & \\
\hline Tobacco & $18.32(10.75)$ & $18.86(11.56)$ & $17.25(12.38)$ & $22.00(10.74)$ & 0.89 & \\
\hline Alcohol & $17.69(8.43)$ & $15.37(8.71)$ & $17.25(7.75)$ & $20.05(8.89)$ & 1.45 & \\
\hline Cannabis & $1.16(2.97)$ & $1.15(2.86)$ & $1.00(3.46)$ & $1.09(3.41)$ & 0.23 & \\
\hline Cocaine & $0.04(0.56)$ & $0.00(0.00)$ & $0.00(0.00)$ & $0.00(0.00)$ & 0.11 & \\
\hline Methamphetamine & $2.64(5.02)$ & $3.34(5.15)$ & $1.92(2.54)$ & $6.59(9.21)$ & 4.53 & $\mathrm{~d} / \mathrm{a}^{*}$ \\
\hline Inhalants & $0.02(0.26)$ & $0.00(0.00)$ & $0.00(0.00)$ & $0.41(1.92)$ & 7.97 & $\mathrm{~d} / \mathrm{a} * *$ \\
\hline Hallucinogens & $0.00(0.10)$ & $0.00(0.00)$ & $0.00(0.00)$ & $0.00(0.00)$ & 0.03 & \\
\hline Opioids & $0.04(0.91)$ & $0.00(0.00)$ & $0.00(0.00)$ & $0.00(0.00)$ & 0.05 & \\
\hline
\end{tabular}

$* p<.05, * * p<.001$

Table 5 shows the significant difference between socioeconomic status and the level of severity of substance use among the Tokhang responders. These results show that the frequency of Cannabis use is very high for the low-income group compare to the low average group $(\mathrm{F}=3.83, \mathrm{p}=.01)$; the findings are the same for methamphetamine $(\mathrm{F}=8.05$, $\mathrm{p}<.01)$.

Table 5: Results of severity level for substance use among tokhang responders and socio-economic status

\section{One-way ANOVA}

\begin{tabular}{|c|c|c|c|c|c|c|}
\hline & Low $^{\mathrm{a}}$ & Low average ${ }^{\mathrm{b}}$ & $\begin{array}{c}\text { High } \\
\text { Average }^{\mathrm{c}}\end{array}$ & High $^{\mathrm{d}}$ & & \\
\hline Variables & $M(S D)$ & $M(S D)$ & $M(S D)$ & $M(S D)$ & $\boldsymbol{F}$ & Scheffe \\
\hline Tobacco & $18.65(10.66)$ & $16.44(11.96)$ & $19.64(10.13)$ & 19.08(9.61) & 2.51 & \\
\hline Alcohol & $17.83(8.48)$ & $17.62(8.21)$ & $17.75(8.64)$ & $15.31(8.22)$ & 1.34 & \\
\hline Cannabis & $1.30(3.03)$ & $1.35(2.97)$ & $0.37(2.56)$ & $0.81(2.89)$ & $3.83 * *$ & $a / b$ \\
\hline Cocaine & $0.05(0.64)$ & $0.04(0.33)$ & $0.00(0.00)$ & $0.00(0.00)$ & 0.33 & \\
\hline Methamphetamine & $3.12(5.53)$ & $2.96(4.77)$ & $1.02(2.77)$ & $0.90(4.19)$ & $8.05^{* *}$ & $\mathrm{a} / \mathrm{b}$ \\
\hline Inhalants & $0.03(0.44)$ & $0.02(0.26)$ & $0.00(0.00)$ & $0.00(0.00)$ & 0.32 & \\
\hline Hallucinogens & $0.00(0.12)$ & $0.00(0.00)$ & $0.00(0.00)$ & $0.00(0.00)$ & 0.17 & \\
\hline Opioids & $0.06(1.08)$ & $0.00(0.00)$ & $0.00(0.00)$ & $0.00(0.00)$ & 0.34 & \\
\hline
\end{tabular}

$* p<.05, * * p<.001$ 


\section{DISCUSSION}

The initial screening among the Tokhang responders is shown in Table 2 which shows that tobacco products have $(\mathrm{M}=19.17)$, followed with Alcoholic beverages $(\mathrm{M}=17.89)$, and identified as moderate risk level respectively. The study by Nordj and colleague (2010) also found similar findings with the most commonly used or abused substances being cigarettes, cannabis, and alcohol [11]. Except for tobacco, alcohol, and marijuana were viewed as the most common drug of choice among young people. Epidemiological studies, mainly carried out in developed countries, suggest that the apparent ease of access to cannabis or marijuana, combined with a lower-risk of harm, makes it the most common substance used after tobacco and alcohol [12]. In Pakistan, heroin was the most abused substance (48\%), followed by cannabis (28\%) [13].

Table 3 shows that there is a significant age-related effect in opioid use $(F=4.27, p<.05)$. As shown by Scheffe result, the 41-50 age group had a significant result in comparison to the other age groups. Current research suggests that people with substance use disorders (SUDs) in later life are undeniably more common than from our initial understanding, and the issue is expected to increase $[14,15)$. As with alcohol, the earlier one starts using drugs, the higher the chance of abuse or becoming dependent on them later in life [16].

In particular, our results showed the significant difference between religion and the severity level of substance use among the Tokhang responders. It was evident that there is a significant effect of Tokhang responders' religion on the use of methamphetamine ( $\mathrm{f}=4.53, \mathrm{p}<.05$ ). That is, Born Again has shown a significant difference in the use of methamphetamine in comparison to other religious groups. The same result was found in the use of inhalants ( $\mathrm{f}=7.97$, $\mathrm{p}<.01$ ). A recent study showed that less intrinsic Christians who use self-directed coping styles were more likely to have SUDs than more intrinsic Christians who will typically use the surrender coping style [17].

Table 5 shows that the severity use of Cannabis is significantly correlated with the low-income group in comparison to the low average group $(\mathrm{F}=3.83, \mathrm{p}=.01)$, the same results were found with methamphetamine $(\mathrm{F}=8.05$, $\mathrm{p}<.01$ ). A similar study indicated low-income, high salary differences among Asians were more associated with a lower risk of SUDs. Whereas for Black ethnicities, low-income was associated with a higher risk of SUDs $[18,19]$. In comparison, the findings of Martin (2019) indicated that participants with high-level of SES were more likely to consume cannabis, use various drugs, utilize alcohol excessively, and drink alcohol and stress-relieving substances than their peers [20].

\section{LIMITATION}

There were several notable limitations to this study. This study was conducted only in the municipality of Don Carlos. Thus, the study findings must be generalized to other programs with caution. Second, the identification and tracking of the Tokhang responders to participate in the screening assessment required significant time, especially in their respective barangays. Finally, not all responders were included in the screening assessment due to either work-related reasons, or could not be located.

\section{CONCLUSION AND RECOMMENDATION}

Screening was first performed on the basis of the SBIRT design. The second was the brief intervention based on the guidelines of the WHO ASSIST tool guidelines in the Tokhang responders. The third was the referral and treatment program. However, this study shows that there was no Tokhang respondent tested for high-risk SUD. Therefore, no one was referred to the Department of Health DOH-treatment and rehabilitation center. Undoubtedly, most of the Tokhang responders will participate for a 6-month period of community-based rehabilitation and treatment intervention. The final screening will be conducted after the intervention program to determine whether there is a significant difference between the initial and final screening of the respondents. A focus group discussion will be conducted to validate and support the results of the study. The initial results of the study will form the basis for the community- based rehabilitation program for the moderate risk responders.

\section{ACKNOWLEDGEMENT}

We would like to express our gratitude to all the tokhang responders who took part of this study from the Municipality of Don Carlos, Bukidnon, Philippines. And to the Addiction Department of Sahmyook University. Authors have no conflicts of interest to report. 


\section{REFERENCES}

[1] Njord, Levi, et al. "Characterizing health behaviors and infectious disease prevalence among Filipino street children." International journal of adolescent medicine and health vol. 20. no. 3, pp.367-374, 2008.

[2] Kulsudjarit, K. "Drug problem in southeast and southwest Asia0". Annals of the New York Academy of Sciences, vol. 1025 no. 1, pp. 446-457.doi:10.1196/annals.1316.055, 2004.

[3] Thompson, M. R. "Bloodied democracy: Duterte and the death of liberal reformism in the Philippines." Journal of Current Southeast Asian Affairs, vol. 35 no. 3, pp. 39-68, 2016.

[4] Hock, R. S., Hindin, M. J., Bass, J. K., Surkan, P. J., Bradshaw, C. P., \& Mendelson, T. "Parenting styles and emerging adult drug use in Cebu, the Philippines." International Journal of Culture and Mental Health, vol. 9 no. 2, pp. 108-119, 2016.

[5] Philippine Drug Enforcement Agency (PDEA). Annual Report 2013.

[6] United Nations Office on Drugs and Crime (2017) World drug report 2017

[7] Elek, E., Miller-Day, M., \& Hecht, M. L. (2006). "Influences of personal, injunctive, and descriptive norms on early adolescent substance use.” Journal of Drug Issues, 36(1), 147-172

[8] Esplanada, J. E. "Chinese drug syndicates behind drug trade in Philippines."Philippine Daily Inquirer. Retrieved from http://globalnation.inquirer.net/41837, 2012/.

[9] Abuse, Substance. "Mental Health Services Administration, Results from the 2010 National Survey on Drug Use and Health: Summary of National Findings, NSDUH Series H-41, HHS Publication No.(SMA) 11-4658." Rockville, MD: Substance Abuse and Mental Health Services Administration pp. 201, 2011, 2010.

[10] Humeniuk, Rachel, Robert Ali, World Health Organization, and ASSIST Phase II Study Group. "Validation of the Alcohol, Smoking and Substance Involvement Screening Test (ASSIST) and pilot brief intervention [electronic resource]: A technical report of phase II findings of the WHO ASSIST Project." 2006.

[11] Njord, L., Merrill, R. M., Njord, R., Lindsay, R., \& Pachano, J. D. "Drug use among street children and non-street children in the Philippines.” Asia Pacific Journal of Public Health, vol. 22 no. 2, pp. 203-211, 2010.

[12] World Drug Report, 2018.

[13] Ghazal, P. "Rising trend of substance abuse in Pakistan: a study of sociodemographic profiles of patients admitted to rehabilitation centres." Public Health, vol. 167, pp. 34-37, 2019.

[14] Humeniuk, R., Dennington, V., \& Ali, R. "The effectiveness of a brief intervention for illicit drugs linked to the alcohol, smoking and substance involvement screening test (ASSIST) in primary health care settings: A technical report of phase III findings of the WHO ASSIST randomized controlled trial." Geneva: World Health Organization, 2008.

[15] Boddiger, D. "Drug abuse in older US adult's worries experts." The Lancet, vol. 372 no. 9650, pp. 1622, 2008.

[16] Maree, R. D., Marcum, Z. A., Saghafi, E., Weiner, D. K., \& Karp, J. F. "A systematic review of opioid and benzodiazepine misuse in older adults." The American Journal of Geriatric Psychiatry, vol. 24 no. 11, pp. 949-963, 2016.

[17]Zhang, C., Brook, J. S., Leukefeld, C. G., \& Brook, D. W. "Developmental Trajectories of Religious Service Attendance: Predictors of Nicotine Dependence and Alcohol Dependence/Abuse in Early Midlife." Journal of Religion and Health, pp. 1-14, 2019.

[18] Lok, S. "Religious coping, motivation and symptoms of substance use disorder: A match made in heaven?" (Master's thesis), 2019.

[19] Chen, Ruijia, Ronald C. Kessler, Ekaterina Sadikova, Amanda NeMoyer, Nancy A. Sampson, Kiara Alvarez, Corrie L. Vilsaint et al. "Racial and ethnic differences in individual-level and area-based socioeconomic status and 12month DSM-IV mental disorders." Journal of psychiatric research vol.119, pp. 48-59, 2019.

[20] Martin, C. C. 2019. "High Socioeconomic Status Predicts Substance Use and Alcohol Consumption in US Undergraduates." Substance Use \& Misuse, vol. 54 no.6, pp.1035-1043, 2019. 